\title{
Three-Dimensional Holey-graphene for Simultaneous Sensing in Biological Fluids
}

\author{
Aihua Jing ${ }^{l}$, Qiong $X u^{1}$, Wenpo Feng ${ }^{1}$ and Gaofeng Liang ${ }^{2, *}$ \\ ${ }^{1}$ School of Medical Technology and Engineering, Henan University of Science and Technology, \\ Luoyang 471023, P. R. China \\ ${ }^{2}$ Medical college, Henan University of Science and Technology, Luoyang 471023, P. R. China; \\ *E-mail: 1gfeng990448@haust.edu.cn
}

doi: $10.20964 / 2019.10 .32$

Received: 2 July 2019 / Accepted: 13 August 2019 / Published: 30 August 2019

\begin{abstract}
The quantification of ascorbic acid (AA), dopamine (DA), uric acid (UA) and tryptophan (Trp) has been an important area of research, as these molecules directly correspond to diagnosing and controlling diseases related to nerve and brain physiology. In our research, novel sensors of threedimensional holey-graphene (3DHGO) were fabricated from holey graphene oxide with nano pores via a reduction method, and their morphology, structure and electrochemical performance were characterized with X-ray diffraction, Fourier transform infrared spectroscopy, scanning electron microscopy, transmission electron microscopy and cyclic voltammograms. The proposed 3DHGO displayed excellent electron transport properties, high sensitivity and selectivity for the simultaneously detection of AA, DA, UA and Trp in healthy human serum and urine samples. This finding paves the way for the application of graphene as a biosensor for medical diagnosis.
\end{abstract}

Keywords: Three dimensional; Holey graphene; Electrochemical biosensor; Simultaneous detection

\section{FULL TEXT}

(C) 2019 The Authors. Published by ESG (www.electrochemsci.org). This article is an open access article distributed under the terms and conditions of the Creative Commons Attribution license (http://creativecommons.org/licenses/by/4.0/). 